\title{
Congenital leukaemia: an unusual cause of stillbirth
}

\author{
E S GRAY, N J BALCH, H KOHLER, W D THOMPSON, AND J G SIMPSON \\ Department of Pathology, University of Aberdeen, Aberdeen, and Department of Pathology, Leeds \\ Maternity Hospital, Leeds
}

SUMMARY Three cases of congenital leukaemia associated with hydrops and intrauterine death are described. The leukaemic infiltrates, which involved both the infants and the placentas, were of monocytic, lymphoblastic, and myeloblastic types, respectively. The general lack of recognition of the condition is probably due to inadequate histological examination of the stillborn infant and the placenta.

Although rare, congenital leukaemia is a condition well recognised by haematologists and paediatricians. From what is known of the kinetics of leukaemic cell generation, ${ }^{1}$ the leukaemic process in affected infants must have been present for some months in utero. This indicates that congenital leukaemia could be a cause of stillbirth, but a search of the published reports has revealed only four recorded cases of such an association..$^{2-5}$ The paucity of published cases suggests that the diagnosis is missed by the pathologist. This is not surprising in view of the low autopsy rate in stillborn infants and the generally poor standard of histopathological examination accorded to such cases.

Two of the three cases described in this report occurred in a single year in the Grampian region of Scotland, while the third was seen several years before in Leeds, England. This third case has been annotated previously, ${ }^{67}$ although with no detailed descriptions.

\section{Case reports}

Case 1. The 21 year old mother was of blood group A, rh D positive and Venereal Disease Research Laboratory (VDRL) negative. Her one previous pregnancy was uneventful, resulting in the birth of a normal child with a birth weight of $3160 \mathrm{~g}$, who was still alive and well. During the present pregnancy she was in good health until 24 weeks' gestation when she developed a monilial vaginitis, which was successfully treated by Clotrimazole Vaginal Tablets. At roughly 34 weeks' gestation the patient noticed that fetal movements had stopped: two weeks later intrauterine death was confirmed by ultrasound examination. After an induced labour she delivered a female stillborn infant weighing
2400 g. Postpartum viral studies on the maternal serum excluded recent infection with a variety of viruses, including cytomegalovirus and herpes

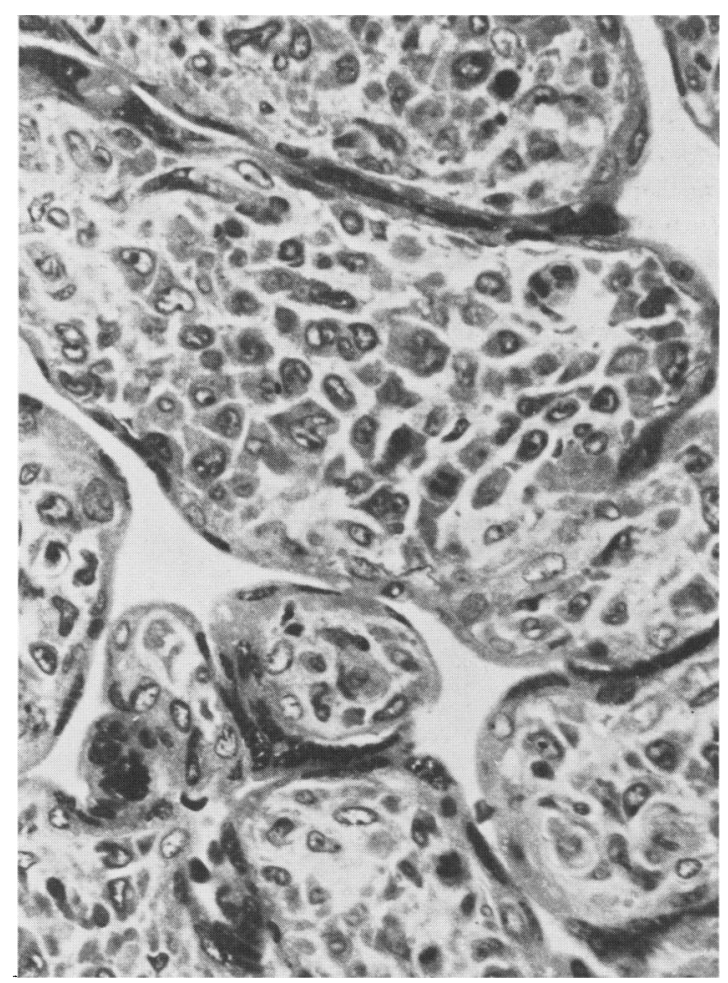

Fig. 1 Chorionic villi in case 1 expanded by histiocytic cells, showing mitotic activity (haematoxylin and eosin staining). 
simplex. The toxoplasma dye test also yielded negative results.

At autopsy on the same day the infant showed mild hydrops and advanced maceration: body weight was $2320 \mathrm{~g}$, indicating some fluid loss from the tissues. Foot length was $7 \cdot 0 \mathrm{~cm}$. There were no external or internal malformations. The liver (which weighed $80 \mathrm{~g})$, spleen $(10 \mathrm{~g})$, adrenals $(3 \mathrm{~g})$, and kidneys $(10 \mathrm{~g})$ were unremarkable. The pleural surfaces of both lungs, however, were diffusely covered by a thin white lesion arranged in a fine reticular pattern. The placenta, which weighed $765 \mathrm{~g}$, was abnormally firm and fleshy. The fetal surface showed several firm pale subchorionic plaques up to $2 \mathrm{~cm}$ in diameter, and the cut surface of the placenta was uniformly pale.

Histology of the placenta showed the chorionic villi to be greatly expanded, with a highly cellular stroma due to diffuse infiltration by fairly uniform cells with large often indented nuclei, a moderate amount of faintly eosinophilic cytoplasm, and a high mitotic rate (Fig. 1). Permeation of the lumina of both the stromal capillaries and of the larger stem vessels by these cells was extensive, but there was no evidence that the trophoblast basement membrane had been breached, and the abnormal cells were not found in the intervillous space nor in the adjacent decidua. Due to advanced autolysis, histological detail of the fetal viscera was poor, but it could be seen that the reticular pattern on the pleura was due

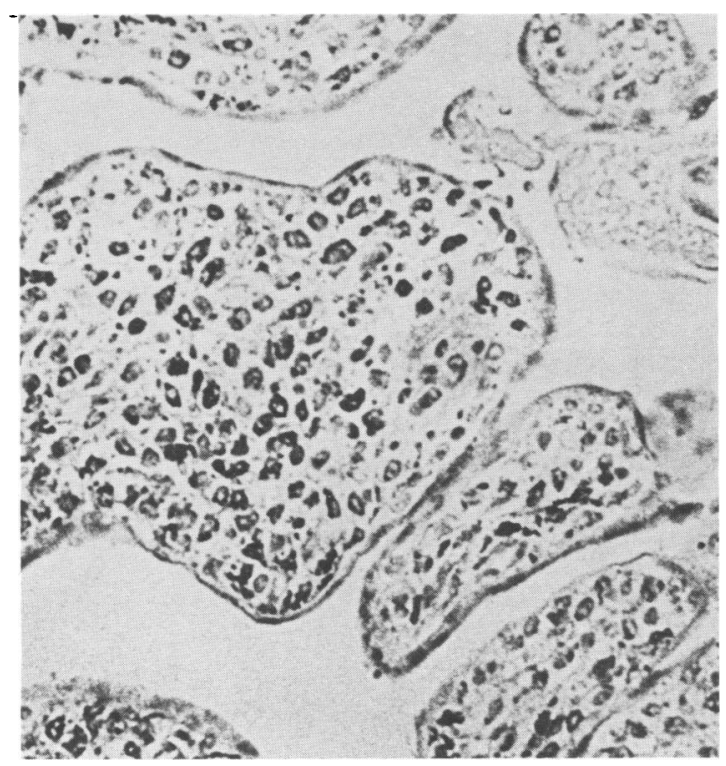

Fig. 2 Heavy cytoplasmic staining for muramidase activity in tumour cells in case 1 (immunoperoxidase staining). to extensive infiltration of lymphatics by cells of similar appearance to those infiltrating the placental stroma and vessels. A similar infiltrate was detected in the liver, spleen, and periadrenal and pericardial fat.

To confirm the initial impression that these cells were histiocytes, immunoperoxidase studies were performed, using the peroxidase antiperoxidase method with antisera to $x$ and $\lambda$ light chains, $\operatorname{IgM}$, IgA, IgG, and IgD heavy chains, muramidase activity, and $\alpha_{1}$ antitrypsin concentration. The last two antiserum samples produced the pattern of granular paranuclear staining typical of monocytichistiocytic neoplastic cells (Fig. 2). Electron microscopy of the placenta confirmed the monocytic/ histiocytic nature of the infiltrate, showing numerous primary and secondary lysosomes, with occasional residual bodies (Fig. 3). The cell borders were rather irregular, with a few microvillous projections, and the vesicular nucleus tended to contain a single nucleolus. These histiocytes did not have the cytoplasmic Birbeck granules described in malignant histiocytes of Langerhans' type.

The light microscopic, immunohistochemical, and ultrastructural appearance all indicated, therefore, that these cells were monocytic (histiocytic) in nature and that this was a case of monocytic leukaemia.

Unfortunately, chromosomal analysis was unsuccessful in this infant.

Case 2. The mother was 26 years of age, blood group rh $D$ positive and VDRL negative. Her two previous pregnancies had been normal, resulting in healthy infants weighing $3500 \mathrm{~g}$ and $3770 \mathrm{~g}$ at term. During the present pregnancy all went well until the 26 th

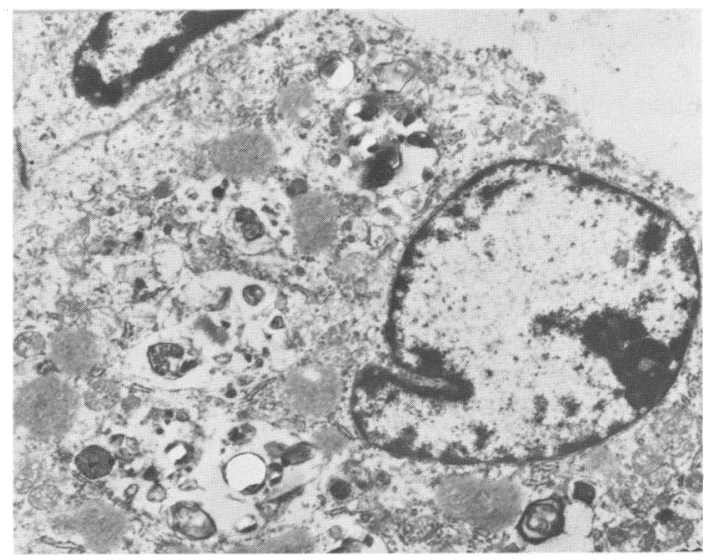

Fig. 3 Electron microscopy of tumour cell in case 1, showing lysosomes and residual bodies. 
week of gestation, when she had what she thought was mumps. For the next two months she had several 'flu like' illnesses. At 34 weeks' gestation she developed premature labour and spontaneously delivered a male stillborn infant weighing $2400 \mathrm{~g}$. Viral antibody titres in the maternal serum showed no evidence of infection with any of the viruses tested, including mumps, influenza $\mathbf{A}$ and $\mathrm{B}$, cytomegalovirus, and herpes simplex. The toxoplasma dye test also yielded negative results.

At autopsy the infant showed moderate maceration and mild generalised hydrops with abdominal distension. The palmar creases were normal and no other external abnormality was noted. The placenta had weighed $800 \mathrm{~g}$ at delivery, but now weighed $550 \mathrm{~g}$ and presented a most unusual appearance, in that the surface vessels running in the chorionic plate to the insertion of the cord were distended by firm yellow 'thrombus' (Fig. 4). Sectioning of the placenta showed that the larger villous stem vessels were also involved. All three vessels of the umbilical cord contained inspissated material, but this was pinkish and more pultaceous, presumably due to autolysis. The pericardial, pleural, and peritoneal cavities contained an increased amount of fluid, which was turbid, a finding unusual in maceration. The pleural surfaces of the lungs were studded with small pale plaques. The most striking feature, however, was that the entire fetal vasculature, including the cerebral vessels, contained pultaceous material similar to that in the umbilical vessels. The cardiac chambers were also distended by this material. The right and left lungs weighed 13 and

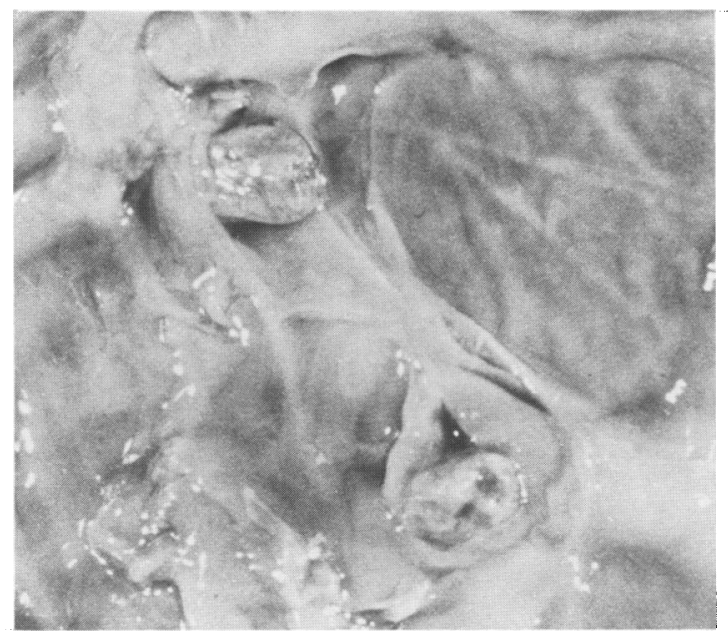

Fig. 4 'Thrombus' protruding from chorionic vessels at cord insertion site in case 2.
$17 \mathrm{~g}$, respectively, and the heart was slightly enlarged at $20 \mathrm{~g}$. There was moderate hepatosplenomegaly (liver $120 \mathrm{~g}$ and spleen $10 \mathrm{~g}$ ). The other organs were normal in weight (kidneys $17 \mathrm{~g}$ and adrenals $4 \mathrm{~g}$ ) and appearance.

Histology showed the intravascular material to be blood in which $80-90 \%$ of the cells were of the white cell series, most apparently being of an undifferentiated blast form (Fig 5 (a) and (b)). The liver and spleen were infiltrated by these cells and there was extensive involvement of the myocardium (Fig. 6), pericardial fat, and pulmonary lymphatics. In the placenta these hyperchromatic cells were confined to the vascular lumina and were not present within the stroma, intervillous space, or decidua.

By light microscopy alone it was not possible to determine whether these cells were myeloblasts or lymphoblasts. Electron microscopy, however, indicated that the cells were of lymphoid origin (Fig. 7). There was a high nuclear:cytoplasmic ratio, the euchromatin nuclei being rounded or ovoid with occasional deep indentations. There were usually two or more nucleoli. The cytoplasm was packed by polyribosomes and none of the cells contained granules. Immunoperoxidase studies, performed as in case 1 , yielded negative results.
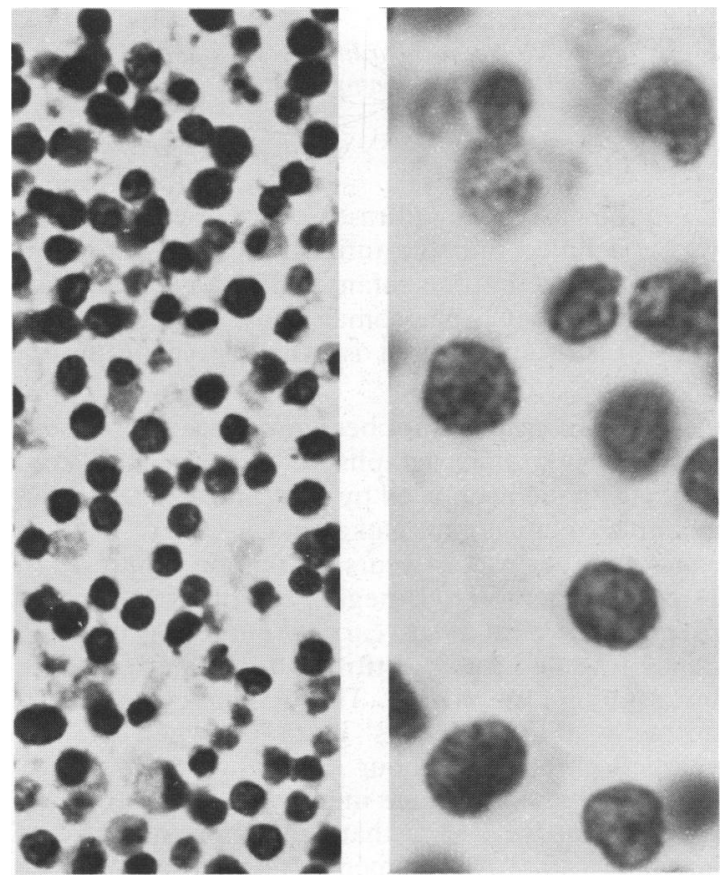

Fig. 5 (a) and (b) Undifferentiated blast cells in 'thrombus' in case 2 (haematoxylin and eosin staining). 


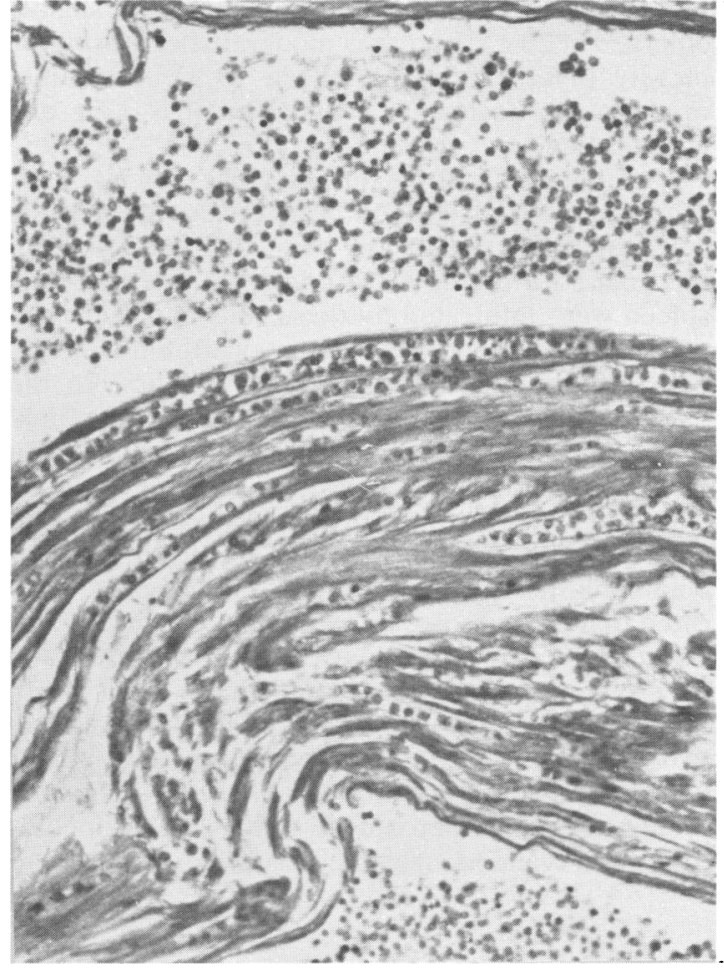

Fig. 6 Infiltration of myocardium by tumour cells in case 2 (haematoxylin and eosin staining).

On the basis of the ultrastructural appearances, it was concluded that the infiltrating cells were lymphoblasts and that this infant had had a lymphoblastic leukaemia. Chromosomal analysis showed a 47, $\mathrm{XY}+21$ karyotype - that is, Down's syndrome.

Case 3. This case has not been previously described, although photomicrographs of the placenta from this baby have been used by Fox ${ }^{6}$ and Becker ${ }^{7}$ as an example of congenital leukaemia.

The mother was 24 years old, blood group A, rh $D$ positive and VDRL negative. This was her first pregnancy. Viral titres carried out early in pregnancy revealed a raised titre to rubella at 1 in 256 , but nothing else of note. The pregnancy continued normally until 35 weeks' gestation when she developed premature labour and delivered a slightly macerated stillborn male infant weighing $2010 \mathrm{~g}$. A toxoplasma dye test at that time showed a titre of less than 1 in 8 . A specimen submitted for evidence of infection by herpes virus also yielded negative results.
At autopsy the male infant weighed $1825 \mathrm{~g}$ and was moderately hydropic. There were no other external abnormalities and the internal viscera, although showing liquefaction, were normal. The placenta was normal in appearance and weighed $475 \mathrm{~g}$. The tentative diagnosis made at autopsy was idiopathic hydrops fetalis. Histology of the placenta showed the villous stroma to be uniformly and densely infiltrated by hyperchromatic, poorly differentiated cells (Fig. 8). No such cells were found in the intervillous space or in the attached decidua.

The umbilical cord vessels were not involved. Although staining of the lungs was poor due to autolysis, it could be seen that the veins and lymphatics were engorged with hyperchromatic nucleated cells similar to those present in the placental villi. The exact nature of these cells could not be determined, but their morphology suggested they were probably immature precursors of the myeloid series and that this was a case of myeloblastic leukaemia.

Chromosomal analysis of fetal tissue was unavailable.

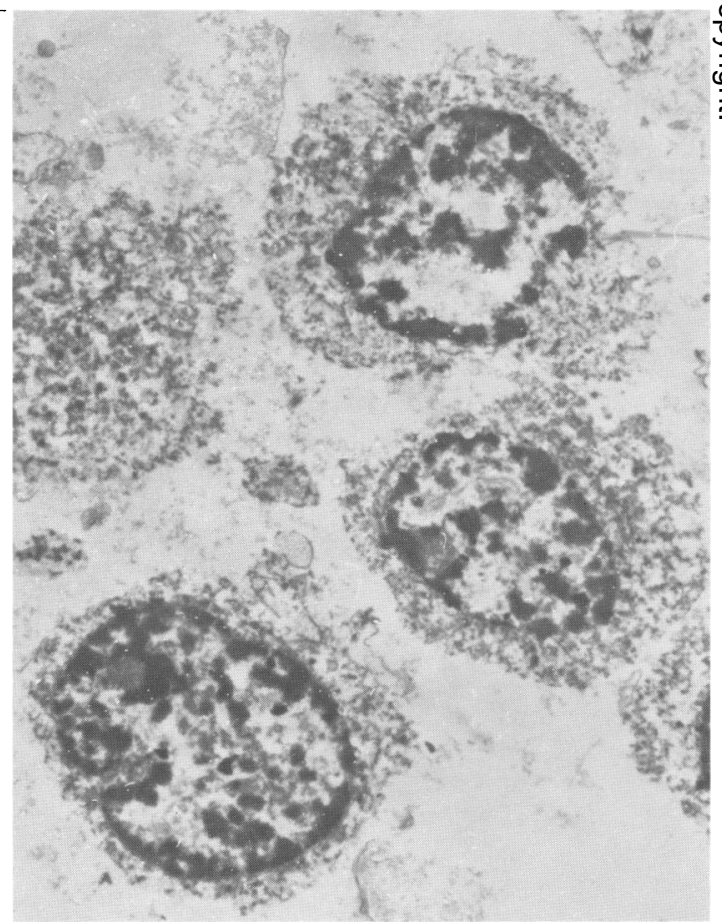

Fig. 7 Electron microscopy of blast cells in case 2, showing lymphoid characteristics. 


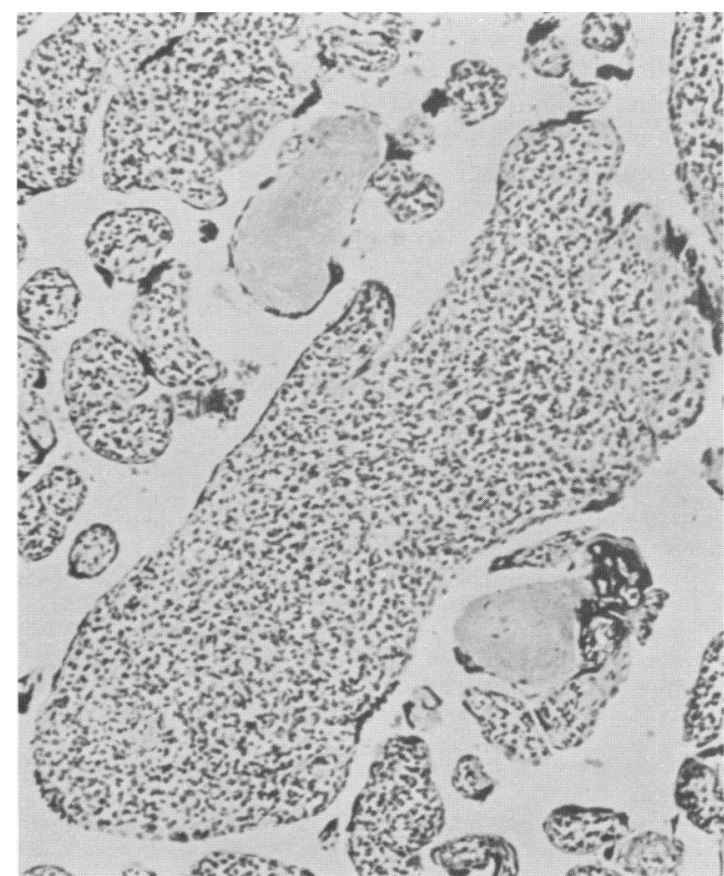

Fig. 8 Dense cellular infiltration of chorionic villi in case 3 (haematoxylin and eosin staining).

\section{Discussion}

In each of these three stillborn infants there was widespread visceral infiltration by cells of a uniform neoplastic appearance. In cases 1 and 3 there was also involvement of the placental stroma but no extension of the tumour cells into the intervillous spaces or maternal decidua. These cells did not metastasise from a primary solid tumour of the fetus. In case 1 both the ultrastructural and immunohistochemical features indicated that the cells were monocytic/histiocytic in origin. In case 2 the cells were less well preserved, but electron microscopy showed that the primitive blast cells were lymphoblasts rather than myeloblasts. In case 3 ultrastructural and histochemical studies were not available, but the infiltrating cells seemed to be of the primitive myeloid series. Because of the nature of the proliferating cells and the massive widespread visceral infiltration of non-haemopoietic organs and vascular involvement, we believe these three stillborn infants had forms of true congenital leukaemia. The possibility that case 1 was an example of malignant histiocytosis was considered, but the cellular infiltrate was more uniform than that found in histiocytosis, there was no erythrophagocytosis, and the ultrastructural features were not those described in histiocytosis $\mathrm{X}$.

Congenital leukaemia is a rare condition, about 100 cases of which have been published. ${ }^{8}$ In many of the early cases the diagnosis was probably incorrect, a point made by Pierce in her review of the cases published, ${ }^{9}$ Some authors believe that congenital leukaemia does not exist and that all the cases reported as such were examples of other fetal or neonatal haematological disorders. ${ }^{10}$ The reason for their scepticism is that the fetus and neonate readily produces a leucoerythroblastic or leukaemoid reaction to a variety of stimuli, including severe haemolysis (as in erythroblastosis fetalis) and congenital infection. This leukaemoid reaction can easily be mistaken for a true leukaemia, both on the peripheral blood films (where the white blood cell count can reach $\left.114 \times 10^{9} / 1\right)$ and on examination of tissue at autopsy.

We feel that we can exclude the possibility of the leukaemoid reaction in these infants on both serological and histological grounds. In the past erythroblastosis fetalis was occasionally mistaken for congenital leukaemia. All three mothers of these infants were rh positive and showed no irregular blood group antibodies on routine serology. Although Coombs tests were not carried out on fetal blood, the infants did not show either the macroscopic or microscopic appearances of severe intrauterine haemolysis. The degree of hydrops was only mild to moderate and the macroscopic visceral changes seen in erythroblastosis fetalis ${ }^{11}$ were not present. There was no histological evidence of chronic fetal red cell destruction, and nucleated red blood cells were not increased.

The leukaemoid reaction can also be produced by intrauterine fetal infections such as syphilis, cytomegalic inclusion disease, rubella, toxoplasmosis, and herpes simplex. Antibodies were not detected to these infective agents in any of the three cases and there was no evidence at autopsy that the fetuses had suffered from any of these conditions.

Septicaemia can produce grossly raised white blood cell counts. ${ }^{12}$ Bacteriological cultures made from lung and spleen revealed a scanty Escherichia coli on enrichment in case 1 and a similar scanty growth of coagulase negative Staphylococcus, but again only in enrichment, in case 2. Both these isolates were probably contaminants. There was no histological evidence of pneumonia or chorioamnionitis in any of the three cases.

Neonates with chromosomal anomalies, particularly those with a trisomy of chromosome 21 (Down's syndrome), often have a congenital or neonatal myeloproliferative disorder, which can be indistinguishable from acute myelogenous leu- 
kaemia. ${ }^{13}$ It has been described as "congenital transient acute leukaemia' ${ }^{14}$ and is probably an ineffective regulation of granulopoiesis masquerading as congenital leukaemia. ${ }^{15}$ It is always of a myeloid type. In case 2 we know that the karyotype was that of Down's syndrome, but the blast cells in the blood in this case were of the lymphoid series. Although the karyotypes of the other two fetuses were not known, neither showed the physical stigmata of Down's syndrome.

Finally, leukaemoid or leucoerythroblastic reactions are so often observed in autopsies on stillborn infants and neonates that the perinatal pathologist is very familiar with that pattern of cell proliferation. In the leukaemoid reaction the infiltrate is polymorphic witis a variety of immature blood cell precursors, the predominant series being myeloid. There is evidence, however, of an orderly progression from blast cells to more mature cell types. Contrary to what is said by some authors, ${ }^{10}$ the leukaemoid reactions can show infiltration of extrahaemopoietic organs, but usually only to a minimal degree. The massive and destructive sheet like infiltration by monomorphic cells showing no maturation, as found in all these cases, is not seen, even in a florid leukaemoid reaction.

The mechanism by which fetal leukaemia could have caused these infants to die in utero is not totally clear, but the moderate degree of hydrops present in all three indicates cardiac failure. Interestingly, none of these cases showed evidence of leukaemic deposits in the skin, a common finding in neonatal leukaemia.

In none of the reported cases of congenital leukaemia has there been evidence of leukaemia subsequently developing in the mother. Two of the mothers presented here were investigated by a haematologist some weeks after delivery, but blood counts and peripheral films yielded normal results. All three mothers have remained well, one in fact becoming pregnant within a few weeks of the stillbirth. This further pregnancy was entirely normal, ending at term with the birth of a healthy baby.
In showing these three cases of congenital fetal leukaemia we wish to refute the claim that the condition does not exist. We also suggest that the rarity of the condition as a cause of stillbirth is more apparent than real, reflecting the general inadequacy of histological evaluation as part of the examination of the stillborn infant.

We are grateful to Mrs I M Watson for typing the manuscript.

\section{References}

1 Greenberg ML, Chanana AD, Cronkite EP, et al. The generation time of human leukemic myeloblasts. Lab Invest 1972;26:245-52.

2 Austarheim K. Kongenit tumordannende leukaemi. Nord Med 1955;54:1380-3.

3 Hogg GR, Schmidt OA. Myelogenous leukemia in a stillborn infant. Can Med Assoc J 1958;78:421-3.

4 Buhtz P. Leukose bei einem Totgeborenen. Zentralbl Allg Pathol 1974;118:489-93.

5 Strauss F, Benirschke K, Driscoll SG: Placenta. Handbuch der spezeillen pathologischen Anatomie und Histologie. Berlin: Springer-Verlag, 1967:291.

6 Fox H. Pathology of the placenta. London: WB Saunders, 1978: 362.

7 Becker HV. Die Plazenta des Menschen. Stuttgart: ThiemeVerlag, 1981:374.

${ }^{8}$ Winstein HJ. Congenital leukemia and the neonatal myeloproliferative disorders associated with Down's syndrome. Clin Haematol 1978;7:147-54.

9 Pierce MI. Leukaemia in the newborn infant. $J$ Pediatr 1959;54:691-706.

${ }^{10}$ Kaufmann HJ, Hess R. Does congenital leukaemia exist? $\mathrm{Br}$ Med J 1962;i:867-8.

1 Larroche J-C. Developmental pathology of the neonate. Amsterdam: Excerpta Medica, 1977;167-77.

12 Holland P, Mauer AM. Myeloid leukemoid reactions in children. Am J Dis Child 1963;105:568-75.

13 Schunk GJ, Lehman WL. Mongolism and congenital leukemia. JAMA 1954;155:250-1.

14 Engel RR, Hammond D, Eitzman DV, Pearson H, Krivit W. Transient congenital leukemia in 7 infants with mongolism. $J$ Pediatr 1964;65:303-5.

15 Ross JD, Moloney WC, Desforges JF. Ineffective regulation of granulopoiesis masquerading as congenital leukemia in a mongoloid child. J Pediatr 1963;63:1-10.

Correspondence to $\mathrm{Dr}$ E S Gray, Department of Pathology, University of Aberdeen, Foresterhill, Aberdeen AB9 2ZD, Scotland.

Received 23 May 1986 